\title{
Japanese nuclear plant in quake risk
}

A nuclear reprocessing plant in northern Japan is sited directly above an active geological fault line that could produce a magnitude 8 earthquake, some earth scientists say.

The massive Rokkasho plant for uranium enrichment, spent fuel reprocessing and nuclearwaste storage is built on an uplifted marine terrace of sloping sedimentary rock layers on the northeast coast of the island of Honshu. According to Mitsuhisa Watanabe, an earth scientist at Toyo University in Tokyo, there is an active fault lying directly under the plant. Watanabe presented his findings on 27 May at the annual meeting of the Japan Geoscience Union in Chiba.

"There is definitely

a fault there that

has been active until recently."

But Japan Nuclear Fuel Limited (JNFL), which runs the plant and is based in Aomori City, disagrees, saying that Watanabe's announcement has "unnecessarily sparked fear in people". JNFL says that seismic reflection profiling shows that no part of the fault line described by Watanabe has seen any action for 1 million years, and that the fault doesn't extend beneath the plant. National guidelines issued in 2006 state that only faults with movement within the previous 120,000 to 130,000 years need be considered active when evaluating earthquake resistance of nuclear facilities. The JNFL survey concluded that there was no reason to fear an earthquake of more than magnitude 6.5 at the site, and that the plant could withstand a 6.9 quake nearby.

Last July, Tokyo Electric Power Company's Kashiwazaki-Kariwa nuclear power plant which was designed to withstand a magnitude 6.5 earthquake - was unexpectedly rocked by one of 6.8 (see Nature 448, 392-393; 2007).

Watanabe analysed JNFL's seismic reflection profiles of the Rokkasho site in addition to his own earth-deformation surveys based on aerial shots taken between February and early May this year. He says that the uplifted structure created some 120,000 years ago shows many signs of deformation since then - characteristic of land sitting over what is called a reverse fault, which he estimates at about 15 kilometres long. "There is definitely a fault there that has been active until recently," Watanabe says. He adds that the fault might link up with an undersea fracture to create a 100-kilometre-long fault capable of pounding the Rokkasho plant with a magnitude 8 earthquake.

Seismology and earthquake-safety specialist Katsuhiko Ishibashi, emeritus professor at Kobe University, agrees with Watanabe that there is probably a 15-kilometre fault directly below the plant. The idea of a longer fault needs further investigation, he says. Either way,
Ishibashi worries that an earthquake larger than expected could inflict serious damage on the plant. "In the worst-case scenario, the whole of northern Japan and even as far as the wider Tokyo area could suffer a serious radiation disaster," he says.

Jim Mori of Kyoto University's Disaster Prevention Research Institute says that Watanabe's conclusions are reasonable, but the data could interpreted in other ways. He recommends further study, including higher-resolution seismic surveys, bore holes drilled into the fault - which would be possible, but probably too costly - and more geological work at sites along its length.

JNFL submitted its seismic report in November 2007 to the Nuclear and Industrial Safety Agency, which is now reviewing it. An official there told Nature that Watanabe's critique would be taken into account, but he did not say what measures would be taken if the possibility of a larger earthquake was borne out.

The Rokkasho plant is at the heart of Japan's plan to reprocess spent fuel for plutonium that can be mixed with fresh uranium. This has met with resistance and the country has yet to decide on a site where it could build a power plant to burn the reprocessed mixed oxide fuel. The current debate is likely to complicate issues. David Cyranoski

\section{UN decision puts brakes on ocean fertilization}

Ocean-fertilization advocates suffered another setback last week as 191 nations agreed to a moratorium on large-scale commercial schemes to mitigate climate change.

The agreement, adopted on 30 May at a meeting of the United Nations Convention on Biological Diversity in Bonn, Germany, calls for a ban on major ocean fertilization projects until scientists better understand the potential risks and benefits of manipulating the oceanic food chain. It took 12 days of diplomatic effort to win the support of Australia, Brazil and China, which had opposed the moratorium.

Fertilization projects typically involve seeding the ocean with some form of iron to stimulate algal growth. The algae absorb carbon dioxide from the atmosphere during photosynthesis. A number of ocean-fertilization companies have been formed, anticipating that they could sell credits for carbon-dioxide reductions into carbon markets, but many scientists question the effectiveness and potential side effects of fertilization.

The new language endorses and broadens a similar warning given last November by 35 countries party to the London Convention and Protocol, which governs ocean pollution. Those nations agreed to study the issue and to establish rules this year.

Dan Whaley, who heads Climos, a San Francisco-based company promoting ocean fertilization, declined to speculate on the impact of last week's decision. But he endorsed the call for more science and said he fully supports efforts to address the issue under the London Convention.

Advocates claim that algal blooms will briefly flourish, then die and drop to the bottom of the ocean, taking atmospheric carbon with them. But there are questions about how much of the algae might be consumed by other organisms or be broken down before sinking, reducing the amount of carbon sequestered. And altering the ocean's ecology may have unwanted effects, such as increased acidity or decreased oxygen levels.

Biological oceanographer Mike Behrenfeld at Oregon State University in Corvallis says the moratorium is justified. "We have no idea how long-term, sustained iron fertilization is going to influence the species composition."

But the only way to find out is through the large-scale experiments that commercial interests are best poised to carry out, says Ken Johnson, a senior scientist at the Monterey Bay Aquarium Research Institute in California.

Johnson is against allowing companies to market carbon credits yet, but he thinks that ocean fertilization is the most viable geoengineering option for addressing a runaway climate. "This isn't something to rush into, but it's the only solution we've got if climate gets out of control." Jeff Tollefson 